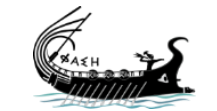

journal.phaselis.org

OPEN
PHAS $\angle L I S$

Disiplinlerarası Akdeniz Araştırmaları Dergisi

Journal of Interdisciplinary Mediterranean Studies

Issue III (2017)

\title{
Rhodiapolis Roma Dönemi Anıt Mezarı
}

The Monumental Tomb of Rhodiapolis from Roman Period İsa KIZGUT

The entire contents of this journal, Phaselis: Journal of Interdisciplinary Mediterranean Studies, is open to users and it is an 'open access' journal. Users are able to read the full texts, to download, to copy, print and distribute without obtaining the permission of the editor and author(s). However, all references to the articles published in the e-journal Phaselis are to indicate through reference the source of the citation from this journal.

Phaselis: Journal of Interdisciplinary Mediterranean Studies is a peer-reviewed journal and the articles which have had their peer reviewing process completed will be published on the web-site (journal.phaselis.org) in the year of the journal's issue (e.g. Volume II: JanuaryDecember 2016). At the end of December 2016 the year's issue is completed and Volume III: January-December 2017 will begin.

Responsibility for the articles published in this journal remains with the authors.

Citation I. Kızgut, "Rhodiapolis Roma Dönemi Anıt Mezarı". Phaselis III (2017) 329-342.

http://dx.doi.org/10.18367/Pha.17020

Received Date: 01.10.2017 | Acceptance Date: 20.12.2017 | Online Publication Date:

30.12.2017 


\title{
Rhodiapolis Roma Dönemi Anıt Mezarı
}

\section{The Monumental Tomb of Rhodiapolis from Roman Period}

\author{
İsa KIZGUT*
}

Öz: Doğu Likya yerleşimi olan Rhodiapolis, Antalya İli, Kumluca İlçesi'nin 2,5km kuzeyinde Sarıcasu Köyü’nün kuzeybatısında, denizden 300 m yükseklikteki tepe üzerinde kuruludur. Makale konusu yapı, kentin güney sınıındaki kaya mezarlarının devamında bulunmaktadır. İkinci kullanım için tamamen temizlendiği anlaşılmaktadır. Girişi doğudan verilen ana mekanın iç duvarları nişlerle donanmıştır. Kuzeyde üç, batıda iç içe iki, güneyde ise iki niş bulunur. Ayrıca, kuzey duvara bitişik bir seki duvar boyunca devam eder. Bu sekiye bitişik zeminde tuğlalarla oluşturulan beş bölme bulunur, girişe en yakın olan bölmede küçük kemik parçaları ele geçmiştir. Mekanın zemini kireç taşı plakalarla kaplıdır. Duvarlardaki nişlerin urne ve ritüellere uygun armağanlar için kullanılmış olabileceği düşünülmüş, zemindeki beş bölmenin ise ölçüleri ve kemik kalıntıları nedeniyle kremasyon gömü için kullanıldığı anlaşılmıştır. İçerisindeki döşemlerin büyük çoğunluğunun kremasyon gömüye yönelik yapılmış olması, niş içerisinde bulunan altlığa büst ya da stel yerleştirilmesi, bölge örnekleri içerisinde bu mezarı özel kılmaktadır. Bu mimari döşemlere göre yapı bir aile mezarlığı olmalıdır. Yapılan konservasyon ile yıkılma tehlikesi olan bölümler, orijinalliğini bozmadan ve çevresine dağılmış olan kendi malzemesi ile onarılmış, niş kemerleri uygun renkte tuğlalarla tamamlanmış, tüm duvarların üstleri yağmura karşı koruma harcı ile kaplanmıştır.

Anahtar sözcükler: Rhodiapolis, Anıtsal Gömüt, Niş, Kremasyon

Abstract: Rhodiapolis, an East Lycian settlement, is located northwesterly from the Sarıcasu village $2.5 \mathrm{~km}$ north of the Kumluca town of Antalya province, upon a $300 \mathrm{~m}$ altitude hill. The building that is the subject of this paper is located further from the rock-cut tombs on the south border of the city. The main room has its entrance to the east and is furnished with niches on its interior walls, consisting three on the north one, two on the west inside each other, and two on the south. Also, a platform runs along the north wall adjacent to it. There are five partitions made of bricks in the floor adjacent to this platform, and bone fragments were found in the one closest to the entrance. The floor of the room is laid with limestone slabs. It was understood that the niches on the wallswere for urns and ritual offerings, and the five partitions in the floor, regarding their dimensions and bone fragments found inside, were for cremation burials. The whole interior being designed for cremation burials and busts or stelae having been placed in the niches on pedestals, are what makes this tomb special. Regarding these architectural furnishings, the building was supposed to be a family tomb. With the conservation, the parts under the risk of destruction were repaired without spoiling its authenticity using their original materials dispersed around. The arches of the niches had to be completed with new bricks with matching colors and all walls were also topped with protective mortar against rain effects.

Keywords: Rhodiapolis, Monumental Burial, Niche, Cremation

Doç. Dr., Akdeniz Üniversitesi, Edebiyat Fakültesi, Arkeoloji Bölümü. ikizgut@akdeniz.edu.tr 


\section{Giriş}

Antalya İli, Kumluca İlçesi sınırlarında yer alan Rhodiapolis Likya Birliği içerisinde tek oy ile temsil edilen, özellikle MS II. yüzyılda en parlak dönemini yaşamış orta ölçekli nüfusa sahip bir yerleşimdir. Gerçekleştirilen kazılarla günyüzüne çıkarılmış eserler MÖ VIII. yüzyıl ile Türk Beyliklerinin gelişi arasında kesintisiz yaşam sürdürülen bir merkez olduğunu kanıtlamıştır. Klasik Dönem kaya mezarları dışında mevcut yapılar Hellenistik ile Geç Hristyanlık Dönemleri arasına tarihlenebilmektedir. Ayakta kalan yapıların büyük çoğunluğu MS II. yüzyılda yaşamış olan Opramoas ve hekim Herakleitos tarafından kente armağan edilmiştir. Asklepieion, Hadrianeum, Opramoas Ailesi Anı Binası, Opramoas Stoası bu yapılardandır ${ }^{1}$. Yerleşimin batı, kuzey ve doğusunu çevreleyen nekropol çok çeşitli mezarlar barındırır².

Makale konusu yapı, yerleşim merkezinin güneydoğusunda, büyük kaya mezarları kütlesinin yaklaşık altmış metre uzağında, doğuya eğimli arazinin alt kotunda ve yeni açılan yol seviyesinden yaklaşık $4 \mathrm{~m}$ yükseklikte yer alır (Fig.1) ${ }^{3}$. Kuzeyde bulunanı daha büyük olmak üzere iki mekanlı yapının çatısı tonozlarla örtülüdür. Ana mekanın tonozu doğu batı doğrultulu iken diğeri kuzey-güney yönlüdür. Yapının tamamı irili ufaklı moloz taş kullanılarak harçla örülmüş, köşelerde ve kapı sövelerinde iri bloklarla güçlendirilmiştir. Eğimli topografya nedeniyle diğer duvarların uygun olmaması mekan girişlerinin doğu yönde yapılmasını zorunlu kılmıştır.

Ana (Büyük) Mekan; $6.95 \times 6.00 \mathrm{~m}$ iç ölçülerindeki yapı dikdörtgen planlıdır (Fig. 2). Yükseklik tonoz dönüşüne dek 5.83, tepe noktası 7.80 metredir. Tonoz tamamen yıkılmış, duvarların üst bölümleri olasılıkla bu yıkılma anında tahrip olmuştur. Yapının doğu duvarı büyük oranda yıkık, sadece alt sıra blokları korunmuştur. Duvarın güney kesimi orijinal değildir. Bu

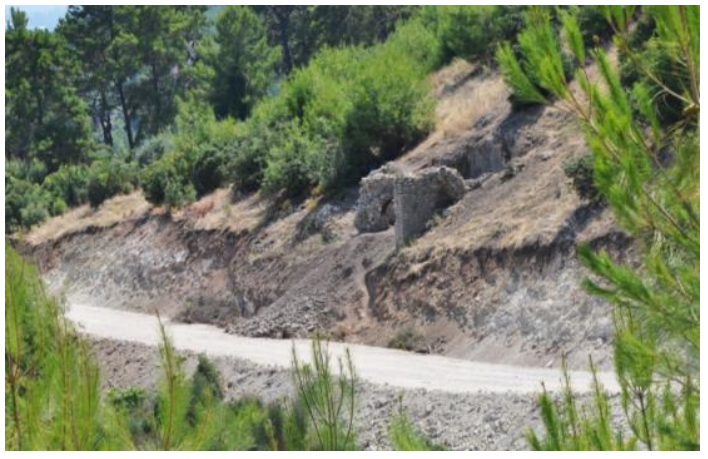

Fig. 1. Rhodiapolis Anıtsal mezar, genel görünüm.

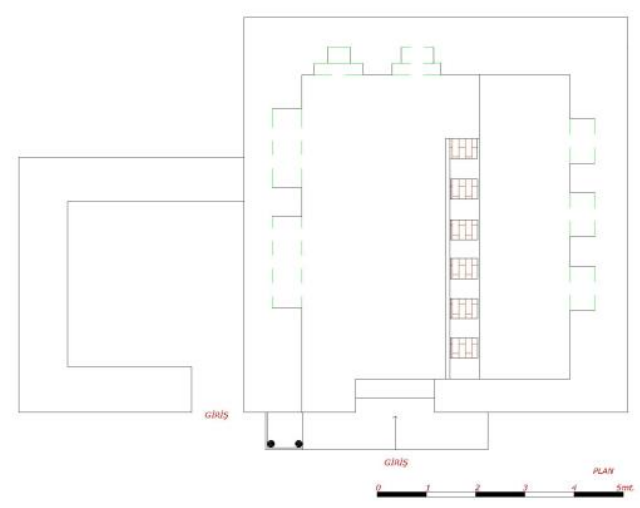

Fig. 2. Ana mekan planı. tahribat ve eklemeler nedeniyle cephe ile birlikte kapı ya da girişin niceliği net olarak bilinememekle birlikte genişliği 0.90 m olduğu anlaşılmıştır. Girişin güneydoğu köşesinde insitu durumda, $0.53 \mathrm{~m} \times 0.53 \mathrm{~m}$ ölçülerinde ve $0.45 \mathrm{~m}$ yüksekliğinde cephesine aslan ayağı kabartılmış bir blok bulunmaktadır (Fig. 3).

1 Rhodiapolis'e ilişkin yayınlar için bkz. Çevik 2005; Çevik 2008; Çevik-Bulut-Kızgut 2008, 1-18; Kızgut 2011, 112-121; Kızgut 2016, 288-299; Özdilek 2011; Tiryaki 2012, 493-514.

2 2006-2012 yılı Rhodiapolis kazılarında elde edilen veriler, ekip üyeleri tarafından kapsamlı bir monografi olarak yayına hazırlanmaktadır.

3 Yapı 2011 kazı sezonu öncesinde kente gidiş gelişin daha rahat sağlanabilmesi için Kumluca Belediye Başkanlığı ile Kumluca Orman İşletme Müdürlüğü tarafından yapılan yol çalışması sırasında açılan yolun hemen kenarında kaldığı için kazı programına alınmış ve iki sezonda tamamlanmıştır. Kazıların 2010 ve 2011 sezonlarında kazısı tamamlanan yapının beliren heyelan tehlikesi nedeniyle projelendirilerek konservasyon çalışmaları yapılmış ve koruma altına alınmıştır. 


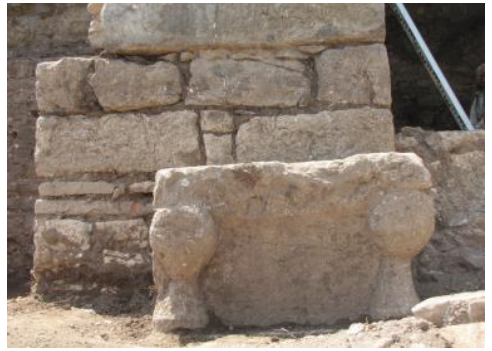

Fig. 3. Aslan ayak kabartmalı blok.

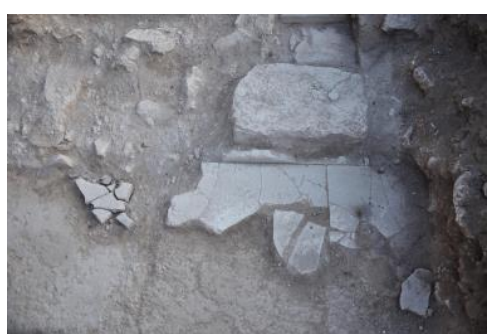

Fig. 4. Zemin kaplama levhaları.

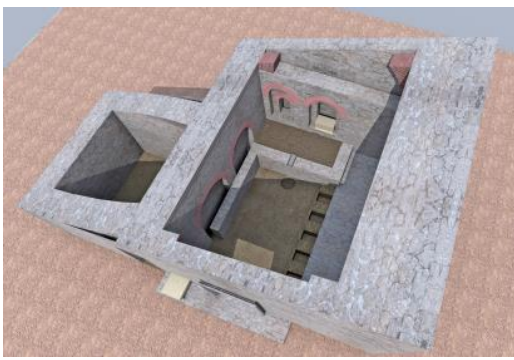

Fig. 5a. Ana mekan 3d modeli

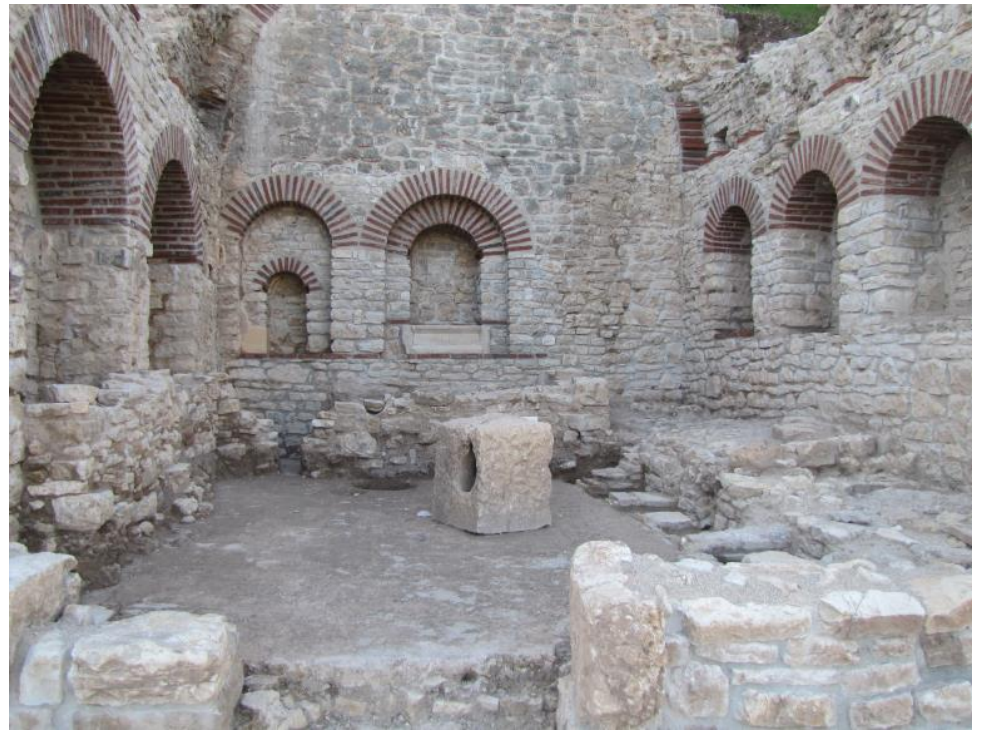

Fig. 5. Zemindeki gömü bölmeleri

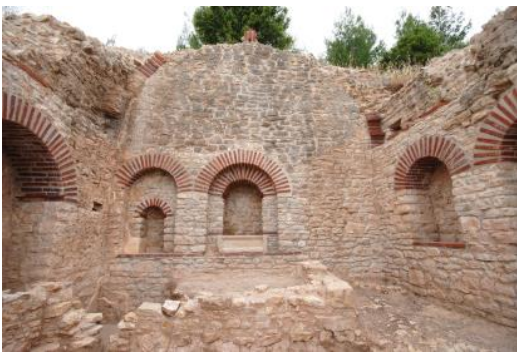

Fig. 6. Batı duvar nişleri

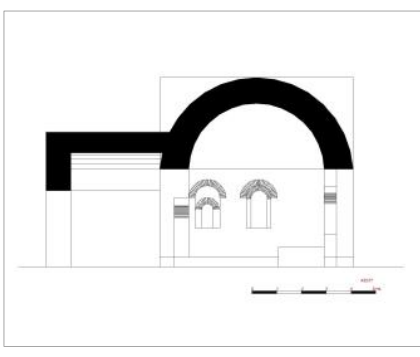

Fig. 6a. Batı duvar nişleri çizim

Orijinal zemine ait kireç taşı kaplama levhaları birkaç yerde insitu kalmış (Fig. 4) ${ }^{4}$, büyük bölümü tahrip olan döşemenin kireç ve kumla oluşturulmuş altyapı zemini sağlam olarak ele geçmiştir. Zeminin temizlenmesi sırasında, kuzey duvarın önünde yer alan podyumun bitimiyle başlayan yan yana 0.55 × 0.40 metre ölçülerinde, ara duvarları tuğla ile örülü 5 bölme açığa çıkarılmış (Fig. 5, 5a, 9a), doğu uçta bulunan bölmeden insana ait kemik parçaları ele geçmiştir.

Bazı bölgelerinde tahribat olsa da büyük oranda korunmuş diğer üç duvar dışta düz bırakılırken içeride çeşitli boyutlardaki nişlerle hareketlendirilmiştir. Nişlerin tamamı aynı form ve boyutta değildir. Girişin karşısında, tonoz başlangıcına dek iyi korunmuş batı duvarda, zeminden 1.10 metre yukarıda başlayan iki niş, güney duvara yakın tutulmuş, kuzey yanda ise daha fazla boşluk bırakılmıştır (Fig. 6, 6a). Güney kesimdeki ilk nişin toplam genişliği yaklaşık 1 m, toplam derinlik ise $0.60 \mathrm{~m}$ olup iç kısımda yine üstü kemerli ikinci niş görünümü oluşturulmuştur. Buradaki yükseklik 0.72 m, dıştaki nişte ise 1.18 metredir. Bu nişin iç ve dış kenarlarında sarı, kırmızı ve siyah renklerden izler taşıyan stüko parçaları görülmektedir (Fig 7). Kuzey kesimdeki niş 0.77 genişlik, 0.28 m derinlik 1.18 m yüksekliktedir. Nişin içerisine kireçtaşından düzgün işçilikli, cephesinde silmeler bulunan $0.77 \mathrm{~m}$ genişlik, $0.32 \mathrm{~m}$ derinlik ve $0.33 \mathrm{~m}$ yüksekliğinde bir blok yerleştirilmiş, bunun da üst yüzeyine çapraz biçimde dikdörtgen formlu bir zıvana, ortasına da bir oyuk açılmıştır (Fig. 8). Bu duvarda nişlerin alt bitim hizasında yine moloz taşlar ile örülmüş ve üzeri harçla kaplanıp kenarları hafifçe yükseltilmiş bir seki oluşturulmuştur (Fig. 6a, 13, 13a).

4 Bu plaka ebatlarının $0.60 \times 0.60$ m ölçülerinde olduğu anlaşılmıştır. 
Yüksekliği 1 metre genişliği ise 5.05 metredir. Sekinin doğu uzun kenarında, güney-kuzey uzantısının yaklaşık ortasına yerleştirilen bir künk çok parçalı olarak ele geçmiştir. Küngün hemen altında mekanın zeminine oyulmuş ve dibe doğru daralan bir çukur tespit edilmiş̧ir (Fig. 13).

Kuzey duvar, nişlerin kemerleri ve en doğudaki nişin üst devamında aşırı tahrip olmuştur. Yaklaşık eşit ölçülerde yan yana üç niş yer almaktadır (Fig, 9, 9a). $0.90 \mathrm{~m}$ genişlikleri, 0.42-0.50 m arasında değişen derinlikleri vardır ${ }^{5}$. Yükseklikleri kemer başlangıcına dek 0.88 metredir. Zeminde kuzey duvarın bitişiğinde ve nişlerin $0.70 \mathrm{~m}$ alt kotunda başlayan, $1.90 \mathrm{~m}$ genişlikte ve doğu duvardan batı duvara dek uzanan $0.50 \mathrm{~m}$ yüksekliğinde bir seki bulunmaktadır. Üzerindeki zemin çok düzgün korunamamıştır (Fig, 5, 9a).

Güney duvarda yer alan iki niş, ölçüleri ile diğerlerinden ayrılır (Fig. 10). Genişlikleri $1.50 \mathrm{~m}$, derinlikleri ise 0.61 metredir. İki nişin yüksekliği birbirine yakındır, kemer dönüşüne dek 1.60, tepe noktada ise 2.37

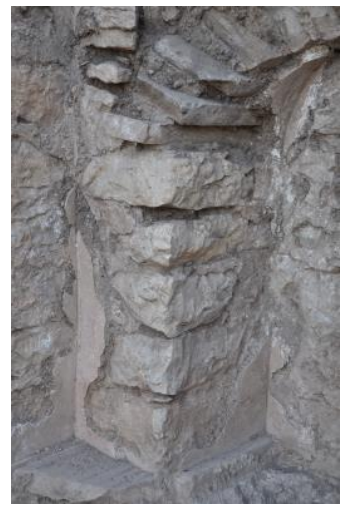

Fig. 7. Stüko parçaları. metredir. İki niş, mekanın zeminine dek devam etmekte ve kireç taşı levhaların buralara dek devam ettiğini gösteren parçalar bulunmaktadır. Nişlerin ortalama 1 metre (korunabilmiş olan) yüksekliğinde moloz taşlarla örülerek önü kapatılmıştır. Tüm nişlerde üst kemerlerin pişmiş toprak tuğla ile örüldüğü korunmuş parçalardan anlaşılmaktadır.

Güney (Küçük) Mekan; ana mekanın güney bitişiğindeki mekan basık tonozla örtülüdür fakat tonozun kapanış yönü ana mekanın tersine doğu-batıdır ve batı bölümdeki bir kısmı korunmuştur. İç ölçüleri 3.50 × 2.75 metre olan mekanın tonoz dönüşüne dek yüksekliği $3 \mathrm{~m}$, tepe noktası ise 4.40 metredir. Girişin bulunduğu doğu duvarı kısmen tahrip olmuş diğer üç duvarı ise daha iyi korunmuş, kuzey duvar ana mekan ile ortaktır (Fig. 11). Tüm duvarlar moloz taşlarla ve harçla örülmüştür. Aralarda az tercih

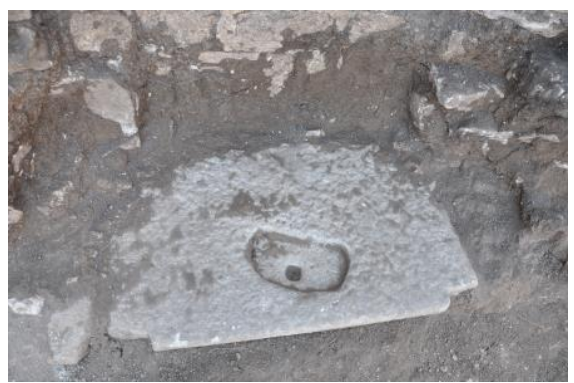

Fig. 8. Üstü yuva açılı blok. edilmiş olsa da seramik kırıkları kullanılmıştır. Küçük mekanın kuzey duvarı büyük mekan ile ortaktır, organik bağlantı olmadan ana mekana eklenmiştir. Deprem nedeniyle tahribata uğramış mekanın zemin kaplamasına dair herhangi bir bulgu ele geçmemiştir.

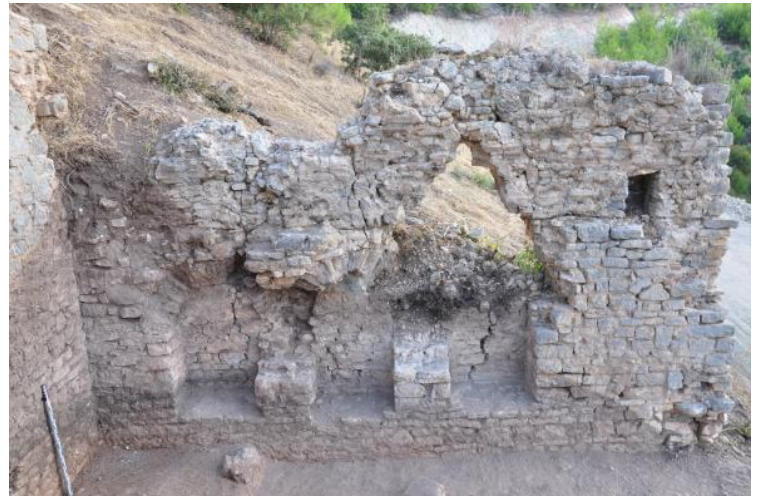

Fig. 9. Kuzey duvar nişleri konservasyon öncesi.

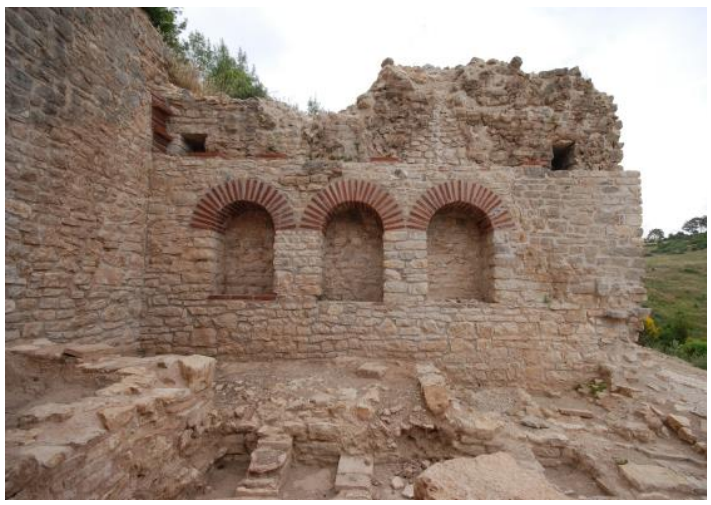

Fig. 9a. Kuzey duvar nişleri konservasyon sonrası.

5 Ölçülerin küçük farklıııları sıvanın korunmamasından kaynaklanması olasıdır. 


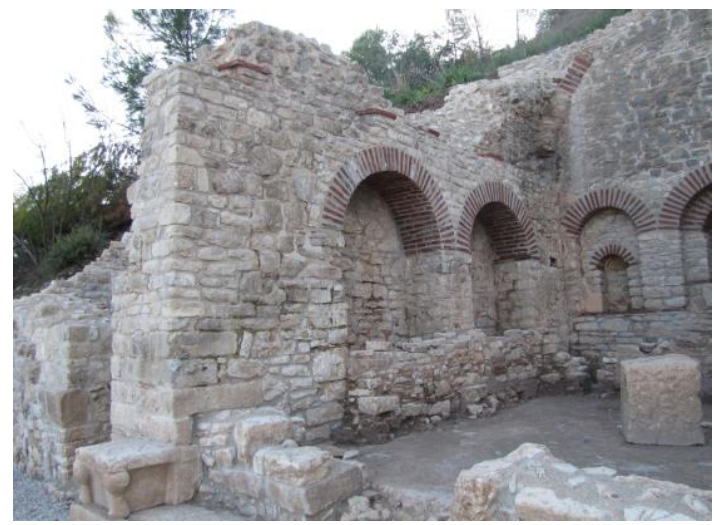

Fig. 10. Güney duvar nişleri.

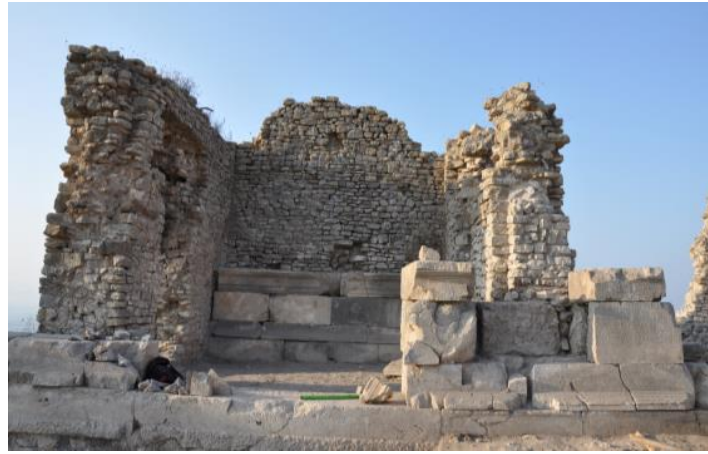

Fig. 12. Opramoas ailesi anı Binası.

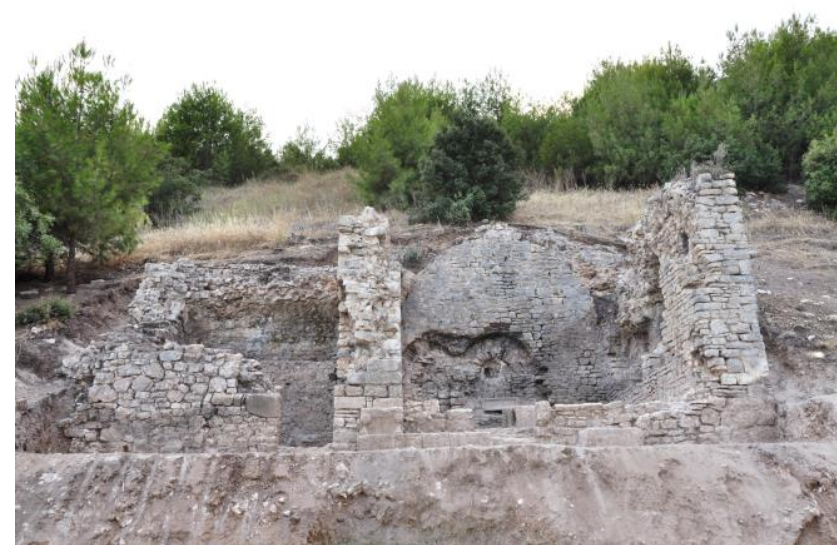

Fig 14. Konservasyon öncesi genel görünüm.

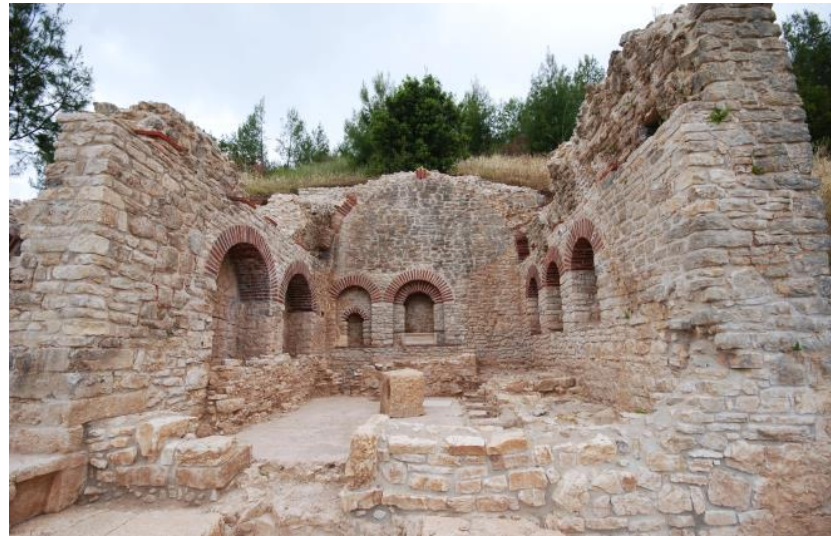

Fig 14a. Konservasyon sonrası genel görünüm.

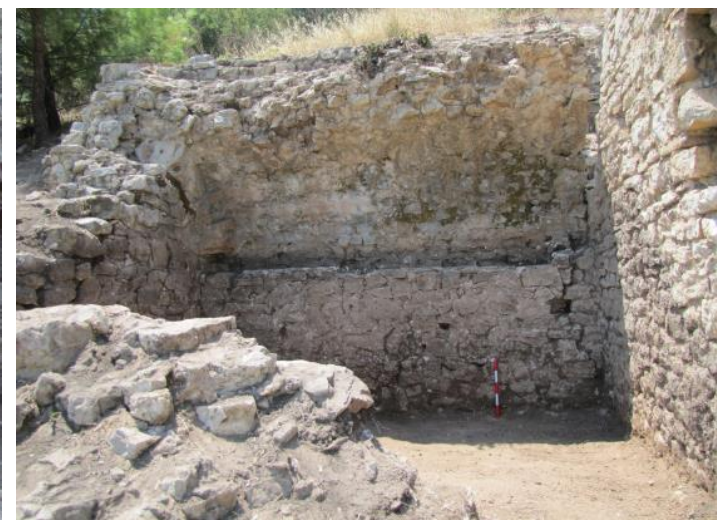

Fig. 11. Yan mekan.

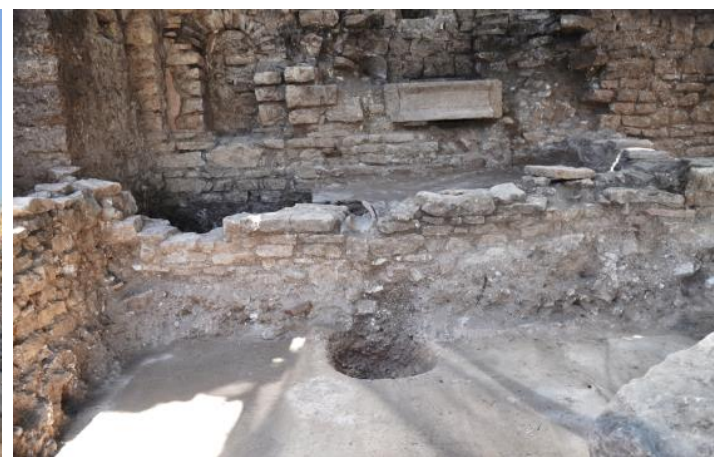

Fig. 13. Üzüm Ezme Teknesi ve Pitos Çukuru.

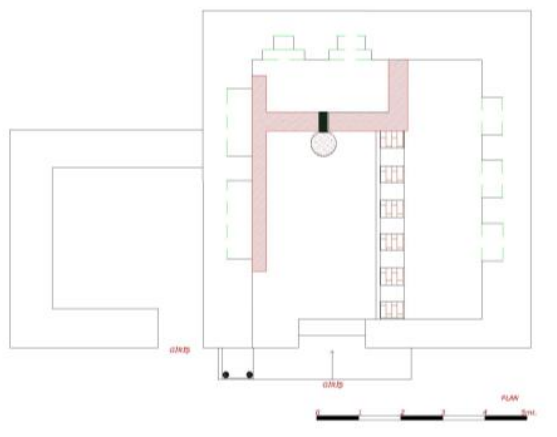

Fig 13a. Üzüm ezme teknesi plan çizim

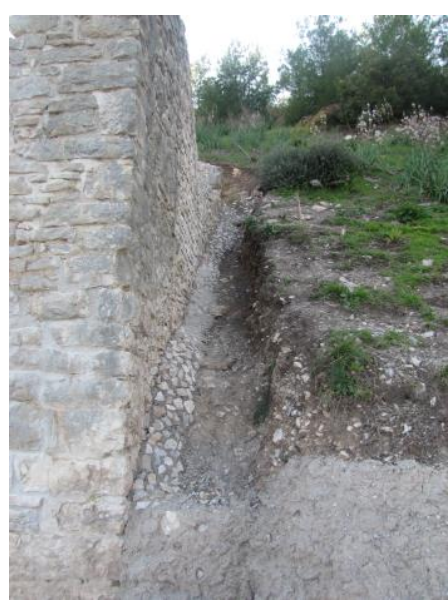

Fig 15. Yapının suya karşı korunması, balık sırtı koruma harcı 


\section{Değerlendirme}

Birinci evre; ana mekanda kuzey duvara bitiştirilmiş sekinin yanı sıra duvarlara açılmış toplam yedi niş ve zeminde oluşturulmuş beş bölme, yapının niceliğini ortaya koyacak döşemlerdir. Nekropol alanında bulunan ve iç düzenlemesiyle mezar olduğu düşünülen yapının kuzey duvarına bitiştirilmiş seki (Fig, 5, 9a), kaya mezarları ile Roma Dönemi'ne ait çeşitli mezar türlerinde yaygın olarak görülen klineleri anımsatır ${ }^{6}$. A. Kızıl bu sekilerin lahit yerleştirme amaçlı olduğunu ve Anemurium örnekleriyle benzer bulduğunu söylemektedir ${ }^{7}$. Ancak Rhodiapolis örneğinde sekinin klineler gibi bir lahit taşımış olabileceği düşüncesi, kuzey duvardaki nişler nedeniyle mümkün değildir. Zira, seki üzerine yerleştirilecek lahit, kuzey duvardaki nişleri kapatacağından bu döşemlerin işlevsiz hale gelmesine neden olacaktır (Fig. 5a, 9a). Diğer taraftan kazılarda da lahit teknesine ait hiçbir buluntunun ele geçmediği dikkate alındığında sekinin, klineler gibi lahit taşıyıcı bir özelliğe sahip olmadığı görülür. Sekinin güneyinde, zemin üzerine tuğlalardan örülmüş beş adet bölme, mezar odası içindeki klinelerde rastlanılan ve bilinen bir uygulama değildir. Bu bağlamda, söz konusu seki üzerine tıpkı kaya mezarları ve oygu gömütlerdeki gibi doğrudan ceset yerleştirilmiş olabilir. Ayrıca, Hierapolis kuzey nekropolünde, kline üzerine yatırılan cesetlerin yanına mezar hediyelerinin de konulduğu tespit edilmiştir ${ }^{8}$. Klinelerin farklı bir kullanımı Stratonikeia'da Akdağ Mevkii'ndeki Hellenistik Döneme ait mezarlarda tespit edilmiş olup mermer ve pişmiş toprak kremasyon kaplarının kline üzerine konuldukları görülmüştür ${ }^{9}$. Dolayısıyla, yukarıda anılan örneklerden sekinin, klinelerdeki gibi ceset ve/veya kremasyon kaplarını taşımaya yönelik inşa edildiğini düşünmek olası görünmektedir.

Kuzey duvarda sekinin korunan zemininden yaklaşık 0.70 metre yukarıda yer alan üç adet kemerli nişin benzerlerine, Olba Bölgesi'ndeki Hisarkale 1 nolu mezarda da rastlanılır. Bu mezarda nişler kline seviyesinde duvarlarda ikişerli olarak, biri ise girişin karşısındaki duvarda bulunur $^{10}$. Küçük boyutlarda olsa da Karia'da Bargylia mezarında yan ve karşı duvarların içine oyulmuş apsis seklindeki küçük kemerli nişler mevcuttur ${ }^{11}$. Patara Kurşunlu Tapınak Mezarı'ndaki kemerli nişler içinde yer alan lahitlerin üst kotunda da nişler bulunmaktadır ${ }^{12}$. Yine Patara 42 nolu oygu mezarda ${ }^{13}$ ve Trebenna'da 9 nolu anıt mezarda ise kemerli olmayan nişler yer almaktadır ${ }^{14}$. Kemerli nişlerin özellikle Roma'daki columbariumlarda yaygın bir kullanıma sahip olduğu bilinmektedir ${ }^{15}$.

Güney duvarda zeminden başlayan iki adet kemerli niş, diğerlerinden büyük olmalarıyla farklılık gösterir. Bu tarz kemerli ve büyük nişlerin Likya'nın Roma Dönemi anıtsal mezarlarında kullanıldığı bilinir. Örneğin, Myra'daki Karabucak Tapınak Mezarı'nın doğu ve batı duvarlarında

Patara Markia Tapınak Mezarı L formlu iki klineye sahiptir. bk. Gülşen 2010, 36, Lev 13, 24; Andriake'de kazılan tonozlu oda mezarlarda üçlü ve tekli ölü yatakları tespit edilmiştir. Söz konusu ölü yatakları, zeminden 10-20 cm. tuğla ile örülerek yükseltilmiştir. Çevik-Bulut vd. 2017, 67-69.

Kızıl 1999, 56.

8 Söğüt 2003, 251 vd., dn. 46.

9 Söğüt 2003, 252.

10 Söğüt 2003, 251.

11 Arıhan 2007, 92.

12 Işık 1995, 161.

13 İşkan-Çevik 1999, 162 Res. 11.

14 Çevik vd.2005, 64, Res. 130.

15 Columbariumlar için genel olarak bk. Borbonus 2014. 
ikişer, güney duvarında ise bir adet niş mevcuttur ${ }^{16}$. Bölgede daha yaygın olanı ise üçlü niş düzenlemesidir. Bunlara örnek olarak Trebenna'dan Lykiarkh Torquatos'un Mezarı ${ }^{17}$ ve Patara Kurşunlu Tapınak Mezarı ${ }^{18}$ gösterilebilinir.

Batı duvarda yer alan iki adet kemerli niş, kuzey duvardakiler ile benzerlik gösterse de, özellikle kuzey yöndeki niş, içinde bir altık barındırıyor olması nedeniyle diğerlerinden farklıdır. Bu özelliği nedeniyle, söz konusu nişin Likya'dan bilinen bir örneği yoktur. Kilikia'nın Olba bölgesinde, mezar odası içinde ve girişin karşısındaki duvarda yer alan ancak kemerli olmayan bir nişin tabanında dübel deliği bulunduğu rapor edilmiştir ${ }^{19}$.

Yukarıda verilen örneklerden de anlaşılacağı üzere, mezar odaları içinde nişlerin bulunması yaygın bir gelenektir. Toynbee, bu durumun özellikle Roma Imparatorluk dönemi için geçerli olduğunu söyler ${ }^{20}$. Ayrıca, yukarıda değinildiği gibi çeşitli türde mezarlarda oda içerisinde kline veya sekilerin bulunduğu görülür. Bu bağlamda, makale konusu yapının kuzey duvarı önünde doğu batı yönelimli sekinin, Hierapolis kuzey nekropolünde ${ }^{21}$ tespit edilen mezar, Trebenna 4 nolu kaya mezarı ${ }^{22}$ ve Andriake Tonozlu Oda Mezarları ${ }^{23}$ ile Patara Oygu Mezarlarında ${ }^{24}$ olduğu gibi ceset yerleştirilmeye yönelik kullanıldığı düşünülebilir. Bunun yanı sıra Karia örnekleri dikkate alındığında, sekiye kremasyon kaplarının konduğunu ${ }^{25}$ hatta ölü hediyelerinin ${ }^{26}$ de buraya bırakılmış olabileceğini düşünmek olasıdır.

Mezar odasının kuzey duvarında üç, batı duvarında ise iki kemerli nişin işlevlerini tespit etmeye yönelik örnekler, Likya, Kilikya, Karia ve özellikle de Roma'daki columbariumlarda karşımıza çıkar. Kilikia Bölgesinde mezar nişlerini inceleyen B. Söğüt, bu tip nişleri kremasyon kaplarına uygun görmekte ${ }^{27} \mathrm{~S}$. Cormak, lotape'den incelediği mezarlardan birindeki nişlerin kremasyon amaçlı olduğunu ${ }^{28}$, E. Rosenbaum da Anemurium mezarlarında da bu tür uygulamalar olduğunu söylemektedirler ${ }^{29}$. Elauissa Sebaste kuzey nekropolündeki iki katlı mezar yapısının üst katında kuzey ve güney, alt katında doğu ve batı duvarlarında yer alan nişleri Machatschek kremasyon $^{30}$, Schneider ise kremasyon yanında üst katta bulunan nişlerin aynı zamanda kült seremonileri için kullanıldığını da öne sürer ${ }^{31}$, Durukan ${ }^{32}$ ve Cormak'da bu yoruma katııır ${ }^{33}$. Kilikia Hisarkale çokgen taş duvarlı örneğinde girişin karşısındaki duvarda bir, yan duvarlarda ise ikişer niş bulunmaktadır. B. Söğüt, sekilerin yukarısındaki nişlerin içine kremasyon gömü yeri

16 Borchhardt 1975, 61 vdd.; Çevik - Bulut 2010, 34 Res. 34-35.

Çevik vd. 2005, 56 vdd., Res. 94-102.

Işık 1995, $161 \mathrm{Abb} .2$.

Akçay 2008, 70 vd., Lev. 32, 36 Fig. 62 Çiz. 14.

Toynbee 1971, 114.

Söğüt 2003, 251 vd., dn. 46.

Çevik vd.2005,68 vd., Res. 143.

Çevik-Bulut vd. 2017, 67-69.

İşkan Yılmaz-Çevik 1995, 187-216.

Söğüt 2003, 252.

Söğüt 2003, 251 vd., dn. 46.

Söğüt 2003, 251 vd.

Cormak 2004, 230 vdd. Fig. 105, 106.

Söğüt 2003, 251 vdd.; Alföldi-Rosenbaum 1971, 14.

Machatschek 1967, 89, Table 52-54 Figs. 68, 69.

Schneider 2003, 263 vd.

Durukan 2005, 110 Fig. 6, 7.

33 Cormak 2004, 218 vd. Fig. 90. 
olabileceğini söyler ${ }^{34}$. Likya bölgesindeki mezar anıtlarından Patara Kurşunlu Mezarı'nda görülen nişlerin, lahitlerin üst tarafına yerleştirildiği ve urne ya da ritüellere ilişkin armağan bırakma amaçlı olabileceği önerilirr ${ }^{35}$. Patara 43 nolu mezarda nişin içinde gümüş bir urne ele geçmiştir ${ }^{36}$. Yine Patara 42 nolu oygu mezarda kemerli olmayan nişin ata kültüne yönelik olduğu tespit edilmiştir $^{37}$. Roma columbariumlarında, kemerli nişler içine urne ve ostothek konulması yaygın görülen bir uygulamadır ${ }^{38}$. Bu durumda, kuzey duvar önündeki seki üzerine ceset bırakıldığı düşünüldüğünde, söz konusu nişler ölü hediyesi veya urne koymaya yönelik kullanılmış olabilirler. Columbariumlar dikkate alındığında, nişler içine küçük boyutlu ostothek konulmuş olabileceği de göz ardı edilmemelidir ${ }^{39}$. Ayrıca, sekinin güney bitişiğinde tuğlalarla örülü 5 bölmenin de benzer şekilde urne koymaya yönelik bir işleve sahip olduğu önerilebilinir. Bu durum batı duvarın güneyindeki niş için de söz konusu olmalıdır.

Güney duvarda bulunan nişler ise büyük ebatları ve zemine dek devam etmeleri nedeniyle farklı işlevde kullanılmış olmalıdır. Zeminleri, mekanda olduğu gibi kireç taşı kaplama levhası ile döşenmiştir. Yukarıda anılan Myra ${ }^{40}$, Trebenna ${ }^{41}$, Patara ${ }^{42}$ ve Olympos ${ }^{43}$ örneklerinde, bu tarz kemerli nişler, içine lahit yerleştirilecek kadar büyüktür. Ayrıca söz konusu nişlerin içinde, zeminden yükseltilen ve lahit oturtulmasına yönelik podyum veya sekilerin de bulunması, makale konusu güney duvar nişlerinden ayrılan bir özelliktir. Bu nedenle güney duvardaki iki nişin ölçüsü ve zemin düzenlemesi, bölge için standart ölçüde bir lahdin oturtulmasına uygun değildir. Dolayısıyla nişler içine ancak küçük (çocuk için) bir lahit ya da ostothek yerleştirilmiş olabileceği düşünülebilinir. Diğer yandan yüksekliklerinin (kemer başlangıcına dek) 2.37m olması bu nişlere heykel yerleştirilme olasılığını da gündeme getirir. Kilikia yerleşimlerinden Semnea'da anteli iki mezarın iç odasındaki nişlerin kremasyon, antedeki (ön odadaki) nişlerin heykel için kullanıldığı söylenmektedir ${ }^{44}$. Termessos örneğinde ise, ele geçen yazıta göre hem heykel hem de lahit bulunmaktadır ${ }^{45}$. Bölge ve komşu bölgelerdeki bu örnekler yanında Rhodiapolis merkezindeki Opramoas Ailesi Anı Binası (Heroonu) örneğinde doğu ve batı duvarlarındaki nişlere aile bireylerinin heykellerinin konduğu yazıtlardan anlaşılır ${ }^{46}$. Kazının tamamlanması ile tonozlu yapının çift kanatlı bir kapısı olduğu anlaşılmış, girişin karşısındaki duvara monteli iri kesme bloklardan oluşan podyum cephesinin üst silmesinin doğu kenarında Opramoas'ın annesinin, batı kenarında ise babasının isimlerinin yazdığı görülmüştür (Fig. 12). Podyumun üzerindeki izlerin ostothek yerleştirme amaçlı olduğu düşünülmektedir ${ }^{47}$. Bu özelliklerle Opramoas Ailesi

Örnekler için bk. Borbonus 2014, 87 Fig. 35, 90 Fig. 37.

Bölgedeki ostothek kullanımının yaygın olduğu bilinen Trebenna için bkz. Çevik-iplikçioğlu 2003, 147-156.

40 Borchhardt 1975, 61 vdd.; Çevik - Bulut 2010, 34 Res. 34-35.

${ }^{41}$ Çevik vd. 2005, 56 vdd., Res. 94-102.

42 Işık 1995, $161 \mathrm{Abb} .2$.

43 Olympos mezarları için genel olarak bkz. Uğurlu 2006.

44 Cormak 2004, 290 vd., fig. 186., 293 vd., fig.

45 Age. 317 vdd., Fig. 213, 214.

46 Rhodiapolis yazıt sorumlusu Prof. Dr. B. İplikçioğlu, buradaki yazıtları deşifre etmiştir. Verdiği bilgiler için teşekkür ederim.

47 Yapının girişinin karşııındaki Opramoas'ın anne ve babasının adlarının yazııı olduğu podyumun üzerindeki izler plinte ya da ostothek için öngörülebilir. Podyumun üzerine heykel yerleştirmek için plinte koyulması 
Anı Binası olarak adlandırılan yapı, makale konusu anıtsal mezar döşemine Rhodiapolis'te en yakın benzer olarak gösterilebilir. Her durumda, bu nişlerin heykel için tasarlanmış olduğunu ispat edebilmek mümkün değildir. Zira, Rhodiapolis örneği dışında (kaldı ki bu da tartışmalıdır), bölgede benzer bir başka örnek bilinmemektedir.

Batı duvardaki iki niş, güney kesimde birbirine yakın yapılmış, kuzeyde geniş bir alan bırakılmıştır (Fig. 6, 6A). Bu planlamanın nedeni nişlerin, güneye yakın olan girişin karşısına getirilme isteği olabileceği gibi kuzey duvarın önündeki sekinin varlı̆ı̆ndan da kaynaklanabilir veya her iki durum birden gözetilmiş olabilir. Söz konusu iki nişin içerisine daha küçük nişlerin farklı formda açılması, diğer nişlere göre işlev farklıığının vurgulanmasından kaynaklanmış olmalıdır. Batı duvarın merkezine yakın duran niş, içinde barındırdığı ve üzerindeki zıvana yuvası bulunan altlığı ile diğerlerinden farkı bir işlevde olmalıdır. Kilikia'da mezar odası içinde ve girişin karşısındaki duvarda yer alan ancak kemerli olmayan bir nişin tabanında bulunan dübel deliği ${ }^{48}$, Toynbee' nin de ifade ettiği gibi niş içerisinde mezar sahibinin porte büstünün konulmasının yaygın bir uygulama olduğunu ${ }^{49}$ göstermesi açısından önemlidir. Mezar içerisindeki nişlerin benzer şekilde büst koymaya yönelik kullanıldığı pek çok araştırmacı tarafından da önerilmektedir $^{50}$. Örneğin, Kilikia'da nişlere yerleştirildiği düşünülen portre büstler tespit edilmiştir ${ }^{51}$. Columbariumlarda da benzer uygulama mevcuttur ${ }^{52}$. Mezar odasının batı duvarının merkezinde yer alan ve bir altlık taşıyan nişin, yukarıdaki örnekler doğrultusunda mezar sahibinin büstünü taşıdığını söylemek mümkündür. Sonuç olarak; kuzey duvardaki sekinin ceset yerleştirilmeye yönelik kullanıldığı, aynı zamanda kremasyon kaplarını taşıdığı ve hatta ölü hediyelerinin ${ }^{53}$ de bunun üzerine konulduğu düşünülebilinir. Sekinin güneyindeki beş bölmenin urne için inşa edildiği, kuzey duvardaki nişler ile batı duvarın güneyindeki nişe ölü hediyesi, urne veya küçük ostothek konmuş olabileceği, güney duvardaki nişlerin ise heykel ya da ostothek konmaya yönelik bir işleve sahip olduğunu söylemek mümkündür.

Mezar odasının güneyine sonradan inşa edilen üstü tonozlu küçük mekanın, kazılarda mimari bir döşem bulunmamış olsa da, mezar sahibinin akrabaları için inşa edilmiş ikinci bir mezar odası olduğu düşünülür. Bu odada hangi tür ölü gömme geleneğinin uygulandığına dair hiç bir veri ele geçmemiştir. Birebir benzeri olmasa da, Patara Bodrum Oda Mezarı́nda, mezarın önünde bulunan ve oda gömütten erken olan lahitler ${ }^{54}$, aynı alanda aile mezarlığının uzun bir zaman diliminde kullanıldığını gösterir.

Rhodiapolis mezarının üst örtüsünü oluşturan tonoz, tuğla ve taş kullanılarak örülmüştür. Cepheden bakıldığında tuğla tonoz, yanda yükselen taş kaplamadan anlaşıldığı üzere görülmez. Bu tekniğin aynı şekilde Rhodiapolis sarnıçlarında kullanıldığı görülmüştür. Patara Bodrum Mevkii oda mezarında ${ }^{55}$, Andriake'deki tonozlu mezarlarda da bu teknik uygulanmıştır ${ }^{56}$.

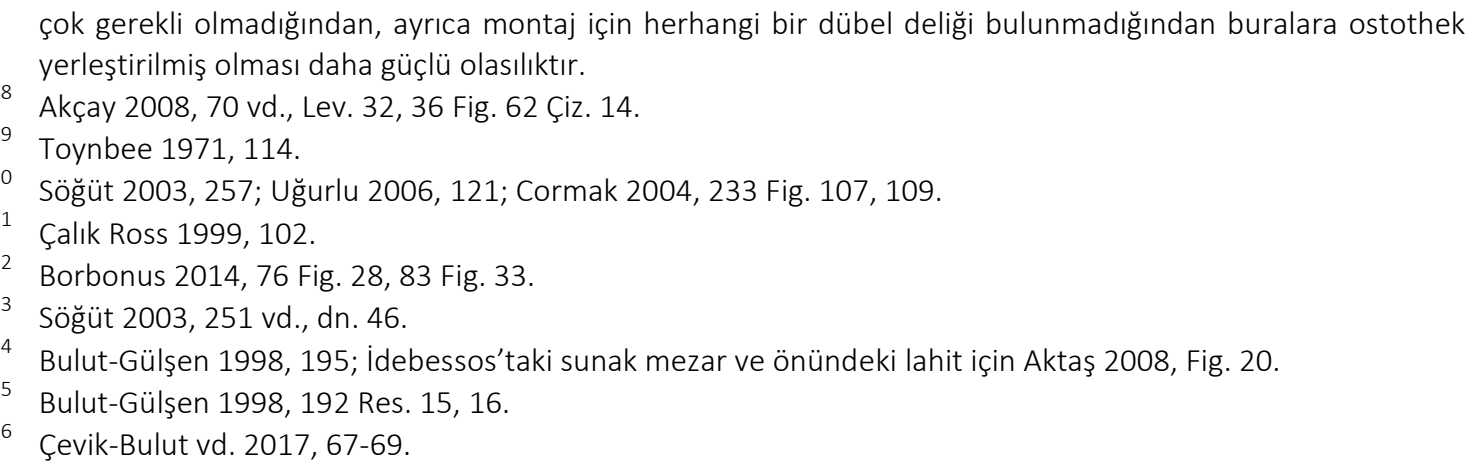


Mezar odası iç duvarlarının sıvandığı ve çeşitli renklerle boyandığı, batı duvarda korunan bir stüko parçası ile anlaşılmıştır (Fig. 7). Bu boyamanın mezar ritüellerine uygun olarak süslemeler içerebileceği de olasıdır. Anemurium mezarları mimari ve duvar örme tekniğinde Rhodiapolis yapılarına benzer ve çoğunun içleri sıvalı ve boyalıdır. Anemurium mezarlarında duvarlar bitki, çelenk ve hayvan motifleriyle süslüdür ${ }^{57}$. Soylu bir aileye ait olduğu önerilen bu yapıda da renkli stükoların süslemeler içerebileceği önerilir.

Girişin güneyinde korunan aslan ayağı kabartmalı blok, mezar yapılarında görülen heykel, sunak yada bir kabı taşıyan kaide olarak kullanılmış olmalıdır.

Mimari tekniği, duvar örgü sistemi ve harç kullanılması Rhodiapolis yapı geleneğinin MS II. yüzyı örnekleriyle birebir benzeşir. Opramoas Döneminin karakteristik yapı tarzında duvarların irili ufaklı moloz taşlar ve harçla örülmesi, içerisinin ya sıvanarak renkli boyalarla süslenip zenginleştirilmesi ya da mermerle kaplanması söz konusudur (Fig. 7 ${ }^{58}$. Kent merkezinde korunmuş olan Hadrianeum, Opramoas Ailesi Anı Binası, Asklepieion ve diğerleri gibi bu yapının ilk evresi de benzer teknikle aynı dönemde inşa edilmiş olmalıdır ve MS II-III. yüzyıla tarihlenmesi uygun görünmektedir.

Rhodiapolis Anıtsal Mezarı, büst, ostothek, urne veya ölü hediyesi taşıyan kemerli nişleriyle Likya'nın Roma Dönemi mezar mimarisi içinde ayrıcalıklı bir konuma sahiptir. Kuzey duvar önündeki sekisiyle birlikte değerlendirildiğinde, mezarda hem kremasyon hem de inhimasyon gömü şeklinin uygulandığı görülür ${ }^{59}$. Bu durum Yunan ve Roma dünyası için de söz konusudur ${ }^{60}$. Bu birliktelik Lykia'da kaya mezarlarında ${ }^{61}$ ve oygu mezarlarda ${ }^{62}$ karşımıza çıkan bir özelliktir. Kremasyon gömü şeklinin erken dönemlerde yaygın olduğu, lahit kullanımının artmasıyla birlikte Roma İmparatorluk Dönemi'nde inhimasyonun da arttığı ve kremasyon gömü tarzının daha çok alt tabakada yaygın bir kullanıma sahip olduğu ${ }^{63}$ genel olarak kabul edilir ${ }^{64}$. Yine Likya'daki bazı mezar yazıtlarında, mezara kölelerin, azatılıarın ya da çok uzak akrabaların defnedilmesine dair bazı formlara rastlanılmaktadır. Bu durumda mezarın hyposorion kısmına, kremasyonun yapılmış olması ihtimal dahilindedir. Nitekim hyposorion girişlerinin ebatları, ekseriyetle $35-35 \mathrm{~cm}$. ya da $40 \times 40 \mathrm{~cm}$.dir. Hyposoriona gömü yapıldığı yazıtlarla kanıtlanmış olduğuna göre, bu açıkıktan ölü küllerinin bir urne içine konarak, buraya yerleştirilmesi makul görünmektedir ${ }^{65}$. Bu düşünce genel olarak doğru olsa da, Rhodiapolis mezarı kremasyon gömü geleneğinin MS II-III. yüzyılda hem de anıtsal bir mezar içinde uygulandığını göstermesinin yanında, mezarın mimari ve iç döşemleri irdelendiğinde, mezar sahibinin söylendiği gibi alt tabakadan biri olmadığı, aksine Rhodiapolis'te yaşayan soylu bir aileye mensup olduğunun bir göstergesidir ${ }^{66}$.

Rosenbaum 1971, Lev. XLIV-XLVIII.

Rhodiapolis Asklepios-Hygeia tapınağında korunmuş izlerden duvarların renkli stükolu, Asklepieion içerisindeki kütüphanenin ise mermer kaplı olduğu tespit edilmiştir.

Likya'da ölü gömme gelenekleri için bk. Uğurlu 2000, 359-378.

Uğurlu 2000, 376.

Trebenna antik kentinin akropol kayalıklarında yer alan Kaya Mezarı 4'te, kremasyon ve inhimasyonun gömü geleneklerinin bir arada uygulandığı görülür. Çevik vd. 2005, 68 vd., Res. 143.

İşkan-Çevik 1999, 165.

Uğurlu 2000, 377 vd.

Bölgedeki kremasyon ve ostothek kullanımı için en önemli yerleşimlerden birisi Trebenna'dır. Buradaki örnekler için bkz. Çevik-iplikçioğlu 2003, 147 vdd.

Uğurlu 2000, 378.

Çevik 2006, 179 vdd. 
İkinci Evre; Yaşanan deprem sonrası biriken yıkıntılar ile ilk evreye ilişkin taşınabilir malzemenin tamamen boşaltıldığı ve ikinci kullanıma hazırlandığı anlaşıımaktadır. Çünkü, yıkılmış olan tonoz ve duvarlara ait hiç bir parça mekan içerisinde ele geçmemiş, yapının güney uzağında bir alana atılı̆̆ı tespit edilmiştir. Batı duvara bitişik yapılan ve üzeri kalın harçla kaplanmış platform, üzerine yerleştirilen künk ve zemine açılan çukur gibi elemanlar mekanın orijinal döşemlerine hem yapısal hem de işlevsel olarak uymamaktadır(Fig. 13). Güney duvardaki iki büyük nişin önüne örülen duvar, söz konusu platformla aynı niteliktedir. Duvarların niteliksizliği, duvar örgüsü içinde ikinci kullanım malzemeler olması platform ve diğer duvarların birlikte düzenlendiğini göstermektedir. Bu eklentilere ve üstünde çift kat harçla oluşturulan zemine bakarak platformun üzüm ezme teknesi olarak kullanılmış olduğu, hemen üstünde yer alan künk aracılığı ile tekneden akan şıranın zemindeki çukura yerleştirilecek pitosa akıtıldığı düşünülmüştür. İki büyük nişin önüne örülen duvarın atölyenin en önemli ihtiyacı olan suyu biriktirmeye yönelik inşa edildiği, mekanın ortalarında ve zemin üzerinde duran iri bloğun ise ağılık taşı olarak kullanıldığı anlaşımıştır.

Döşemlerdeki değişiklik ve yapılan eklemeler yapının ikinci kullanımda şarap işliğine dönüştürüldüğünü, yapının ilk işlevinin tamamen değiştiğini göstermektedir. İkinci evredeki kullanıma ait taşınabilir malzemenin illegal kazııılar tarafından alındığı anlaşımaktadır. Bu nedenle yapılan kazılarda ele geçen buluntular tarihlemeye yardımcı olamamıştır. Çevrenin tarıma elverişli ve sulak olması, mekanın işlik için yeterliliği yapının yeniden kullanılmasında önemli etkenlerdir. Söz konusu eklemelerin, tonozun yıkılarak mezar işlevinin sona ermesiyle özensiz ve düzensiz işçilikle yapılması gibi özellikler, yapının kent merkezinin korunma duvarıyla küçültüldüğü Bizans Dönemi içerisinde şarap işliğine dönüştürüldüğü düşüncesini doğurur. Şarap işliklerinin fermantasyon için güneş ışığına ihtiyaç duyması nedeniyle açık alanlarda yapılması tercih edildiği ${ }^{67}$ düşünüldüğünde, makale konusu yapı olasılıkla yaşanan deprem sonrası tonozunun tamamen çökerek üstü açık bir mekana dönüşmesi ardından şarap işliği için uygun bir duruma gelmiş olmalıdır.

Konservasyon; Yapının önceki konservasyon durumuna bakıldığında deprem yıkığı, ikinci kullanım ve yasadışı kazılarla oluşan bütün tahribatlar yapıyı bütünüyle bozamamış temel mimari özellikleri koruna gelmiştir. Kuzey duvarda bulunan nişlerdeki tahribat duvarın zaman içerisinde yıkılmasına neden olacak boyutlardaydı. Batı duvarın önünde yer alan üzüm ezme teknesinin güney bölümü (1.89 m x 1.25 m) ile büyük nişin ortası kaçak kazıcılar tarafından kazılarak delinmişti. Küçük mekanda duvarlar genel olarak korunmuş olup üst örtüsü (tonozun büyük bölümü) yıkılmış durumdaydı. Yapının tamamında duvar örgüsünde kullanılan kireç harcı erimiş, derzlerde toprak birikmiş, bu durum bitki üremesine neden olmuştur. Bütün bu olumsuzlukların önlenmesi, yapının korunması, algılanabilirliğinin arttırılması için Kültür Varlıkları ve Müzeler Genel Müdürlüğü izniyle konservasyonuna karar verilip projesi hazırlanmıştır. Antalya Bölge Koruma Kurulu onayından sonra uygulamaya geçilmiştir.

Kente ulaşımı sağlamak için yeni bir yol açılması sonrasında yağan yağmurlarla oluşan heyelan, yapının kayma riskini ortaya çıkarmıştır. Bunun üzerine kaymasını önlemek için yapının önüne istinad duvarı örülmesi kararlaştırılmış ve konservasyon projesine eklenmiştir. Koruma duvarı örülürken yapının duvar derzlerindeki topraklar temizlenmiş sonrasında buharla yıkanmıştır. Hidrolik kireç, kum ve reçineden yapılan harç ile boşalmış olan derzler doldurulmuştur. Daha sonra duvarlardaki küçük yıkıklar, kemerlerin oturduğu ayaklar tamamlanıp kemerler için yapılan

67

Bulut 2005, 193 dn. 18. 
kalıplar yerleştirilmiş ardından yapının dokusuna en uygun renkte tuğlalar bulunarak kemerler örülmüştür. Kemerlerin üzerindeki duvar yıkıkları tonozun başlangıç noktasına kadar tamamlanmışır.

Her iki dönemin özelliklerini korumaya özen göstererek yapının içindeki geç dönem eklentileri de derz çalışması ile sağlamlaştırımıştır. Kaçak kazı ile ezme teknesindeki delinen zemin harç ile kapatılış, duvarlardaki renkli boyanmış stüko parçacıkları enjeksiyon harcı ile koruma altına alınmıştır. Küçük mekanın duvarlarında da derz dolgu çalışması yapılmış, duvarların üstleri ve arkasına koruma harcı yapılarak yağmurdan korunması sağlanmıştır (Fig. 14, 14a).

Son olarak yapının tüm duvarları toprak seviyesinde moloz taş ve harç kullanılarak balık sırtı formunda bir katman oluşturulmuş, böylelikle yapı temelinin sudan korunması sağlanmıştır (Fig. $15)^{68}$. Yapının yıkık bölümlerinin tamamlanmasında Venedik Kriterleri'ne uyularak yeni örülen yerlerin ayrımı belirtilmiştir. Bu onarımda kullanılan taşlar yapının kendi yıkıntısı içinden, istinad duvarının örülmesinde ise yerleşimdeki yapıların yıkıntılarının oluşturduğu atık taş tarlasından elde edilmiştir. 


\section{BIBLIYYOGRAFYA}

Akçay 2008

Aktaş 2008

Alföldi-Rosenbaum 1971

Arıhan 2007

Borbonus 2014

Borchhardt 1975

Bulut-Gülşen 1998

Bulut 2005

Cormack 2004

Çalık Ross 1999

Çevik-Iplikçioğlu 2003

Çevik vd. 2005

Çevik 2006

Çevik 2008

Çevik-Bulut-Kızgut 2008

Çevik - Bulut 2010

Çevik 2015

Çevik-Bulut vd. 2017

Durukan 2005

Gülşen 2010

Işık 1995

İşkan Yılmaz- Çevik 1995 İşkan-Çevik 1999

Kızgut 2011

Kızgut 2016
T. Akçay, Olba Mezarları. Yayınlanmamış Yüksek Lisans Tezi, Gazi Üniversitesi, Ankara 2008

S.. Aktaş, "Tombs of the Exedra Type and Evidence from the Patara Examples" Adalya XI (2008), 235-262.

E. Alföldi-Rosenbaum, "Anamur Nekropolü". Türk Tarih Kurumu Yayınları, Ankara 1971.

S. Karaöz Arıhan, Karia Bölgesi Ölü Gömme Adetleri. Yayınlanmamış Yüksek Lisans Tezi, Ankara Üniversitesi. Ankara 2007.

D. Borbonus, Columbarium Tombs and Collective Identity in Augustan Rome. Cambridge University Press, USA 2014.

J. Borchhardt, "Myra. Eine lykische Metropole in antiker und Byzantinischer Zeit". Istanbuler Forschungen 30 (1975).

S. Bulut-F. F.Gülşen, "Patara - Bodrum Oda Gömütü” Adalya II, 1998, 189-204.

S. Bulut, "Likya-Pamfilya-Pisidya Sınır Bölgesinden Sıradışı İki Zeytinyağı Iş̧liği". Adalya VIII,(2005) 191-210.

S. Cormack,"The Space of Death in Roman Asia Minor" Viyana 2004.

A. Çalık Ross, "Local Funerary Busts from Kilikia", Asia Minor Studien 34, (1999) 101-110.

N. Çevik, "Neues zu den Felsostotheken in Trebenna" EA (2003) Heft 35, 147156.

N. Çevik-B. Varkıvanç-S. Bulut-i. Kızgut, "Roma Dönemi Kalıntıları” Eds. N. Çevik -B. Varkıvanç- E. Akyürek, Trebenna Tarihi, Arkeolojisi ve Doğası. Antalya (2005) 31-130.

N. Çevik, "The social structure as reflected through the necropolii of Trebenna" III. Likya Sempozyumu. Antalya (2006) 175-207.

N. Çevik, "Rhodiapolis ve Kumluca Sınırları İçindeki Diğer Antik Yerleşimler", Ed. N. Çevik Arkeolojisi, Tarihi, Doğası ve Tarımıla Kumluca Rhodiapolis. Antalya 2008.

N. Çevik- S. Bulut- I. Kızgut, "Rhodiapolis Kazılarında IIlk Yıl: 2006", KST XXIX. II, Kocaeli. 2008. Ankara.

N. Çevik - S. Bulut, "Ikinci Kazı Sezonunda Myra ve Limanı Andriake", bk.:N. Çevik (ed.), Arkeolojisinden Doğasına Myra-Demre ve Çevresi. Kültür Bakanlığı Yayınları (2010) 23-113. Antalya.

N. Çevik, Lykia Kitabı, İstanbul 2015.

N. Çevik - S. Bulut - A. Aygün - Ö. Çömezoğlu Uzbek, "Myra and Andraike Excavations of 2016. 2016 Yılı Myra Andriake Kazıları" ANMED 15 (2017) 67-75.

M. Durukan, "Monumental Tombs Form in The Olba Region" Anatolian Studies 55 (2005) 107-126.

F. F. Gülşen, Patara Markia Anıt Mezarı Mimarisi ve Restitüsyonu, Yayınlanmamış Doktora Tezi, Akdeniz Üniversitesi. Antalya.

Işık, F., "Tempelgraber von Patara und ihre Anatolischen Wurzeln" Lykia II. 160-186. Antalya.

H. İşkan Yılmaz - N. Çevik, "Die Grüfte von Patara”, Lykia 2, 1995, 187-216.

H. İşkan - N. Çevik, "III. Nekropol Kazıları. 1. Oygu Mezarlar" Bk. F. Işık, Patara 1997, KST 20/2 (1999) 159-178.

i. Kızgut, "Bir Hayırseverin Yarattığı Kent: Rhodiapolis", Aktüel Arkeoloji Dergisi 20 (2011).

i. Kızgut, "Hayırsever Opramoas'ın Kenti: Rhodiapolis", Eds. H. İşkan- E. Dündar, Lukka'dan Likya'ya Sarpedon ve Aziz Nikolaosun Ülkesi. İstanbul 
Kızıl 1999

Machatschek 1967

Özdilek 2011

Schneider 2003

Tiryaki 2012

Toynbee 1971

Uğurlu 2000

Uğurlu 2006
(2016) 288-299.

A. Kızıl, Karya Bölgesi Roma Dönemi Anıt Mezarları. Yayınlanmamış Doktora Tezi, Selçuk Üniversitesi, Konya 1999.

Machatschek, A., Die Nekropolen and Grabmaler im Gebiet Elauissa Sebaste und Korykos in Rauhen Kilikien. Wienna 1967.

B. Özdilek, Rhodiapolis ve Lykia Tiyatroları. Yayımlanmamış Doktora Tezi, Akdeniz Üniversitesi. Antalya 2011.

E. E. Schneider, "Some considerations on Elauissa's North-Eastern Necropolis" Olba VII (2003) 261-273.

A. Tiryaki, "Rhodiapolis Piskoposluk Kilisesi'ne ait Bir Grup Korkuluk Levhası", Olba XX (2012) 493-514.

J. M. C. Toynbee, Death and Burial in the Roman World, London 1971.

E. Uğurlu, "Likya Bölgesi Ölü Gömme Adetleri Üzerine Genel Bir Bakış" Anadolu Üniversitesi Edebiyat Fakültesi Dergisi I/2, 359-388.

E. Uğurlu, Olympos Nekropolü Yayınlanmamış Doktora Tezi, Ankara Üniversitesi. Ankara 2006. 